\title{
ST Segment Depression in 12 lead ECG and Severity of Coronary Artery Disease in Non-ST segment elevation Acute Coronary Syndrome
}

\author{
Mohammad Emdadul Hoque Miah ${ }^{1}$, Abul Hussain Khan Chowdhury ${ }^{2}$, Khandaker Qamrul Islam², \\ Mir Jamaluddin², Shakil Ghafur ${ }^{3}$, Md. Khalequzzaman², Mohammad Ullah ${ }^{2}$ \\ 1250 bedded general hospital, Gopalgonj, ${ }^{2}$ National Institute of Cardiovascular Disease, Dhaka, \\ Department of Cardiology, Sheikh Abu Nasser Specialized Hospital, Khulna
}

\begin{abstract}
Keywords: Acute coronary syndrome, unstable angina, non ST segment elevation acute coronary syndrome, coronary artery disease.
\end{abstract}

\begin{abstract}
Background: Patients of non-ST segment elevation acute coronary syndrome (NSTE ACS) is a large group who gets admitted in coronary care units. 12-lead electrocardiogram (ECG) provides the simple available and earliest objective information for risk stratification of NSTEACS. We tried to find out the association between magnitude of ST segment depression and angiographic severity in NSTE ACS patients.

Methods: This cross sectional study was carried out in patients with NSTE ACS patients admitted into and underwent coronary angiography. A total number of 105 consecutive patients were included in this study. ST segment depression was measured and categorized according to magnitude of ST segment depression into three groups as Group I: No $(<1 \mathrm{~mm})$ ST segment depression, Group II: 1-2 $\mathrm{mm}\left(e^{\prime \prime} 1\right.$ to $\left.<2 \mathrm{~mm}\right)$ ST segment depression and Group III: e" $2 \mathrm{~mm}$ ST segment depression. Cumulative sum of ST segment depression and number of leads in ST segment depression also measured in all ECG leads. Angiographic severity was assessed by vessel score and Friesinger index. Significant $C A D$ was considered if Friesinger index was e" 5. Magnitude of ST segment depression was correlated with angiographic severity of coronary artery disease.
\end{abstract}

Results: According to 'Friesinger index' 56(53.33\%) patients had significant CAD and 49(46.66\%) patients had insignificant CAD. Magnitude of ST segment depression found to have significant relationship with severity of coronary artery disease $(p<0.001)$. Number of leads in $S T$ segment depression also revealed positive correlation $(r=0.446 ; p<0.001)$. Positive correlation was also found between sum of the ST segment depression and Vessel score $(r=0.435 ; p<0.001)$.

Conclusion: Magnitude of ST segment depression is positively correlated with the angiographic severity of coronary artery disease in non-ST segment elevation acute coronary syndrome.

(Cardiovasc. j. 2017; 9(2): 116-121)

\section{Introduction:}

Coronary heart disease (CHD) is a major cause of mortality globally and this health problem is reaching epidemic in both developed, as well as, in developing countries. ${ }^{1}$ It will be the leading cause of disability worldwide by the year $2020 .{ }^{2}$ Non-ST segment elevation acute coronary syndrome (NSTE ACS) accounts for approximately 2-2.5 million hospital admission annually worldwide. ${ }^{3}$ MA Siddique has explained that multiple cardiovascular risk factors along with ignorance about risk factors as a cause of recent increases of occurrence of unstable angina in Bangladesh. ${ }^{4}$ Rapid risk stratification is crucial for appropriate management of this group of patient. Prognostic value of ST segment deviation (both elevation and depression) was studied in the Thrombolysis In Myocardial Ischemia (TIMI) III registry by Cannon CP 1997. ${ }^{5}$ Specifically prognostic value of ST segment depression in coronary artery diseases was assessed by various studies. ${ }^{6-13}$

Kaul et al. found that a categorical quantification of the amount and distribution of ST segment depression can identify a gradient of risk independent of clinical variables. ${ }^{10}$ This study has shown that patient with ST segment depression of $\geq 2 \mathrm{~mm}$ in two contiguous leads was approximately six times (odds ratio 5.73; 95\% CI) more likely to

Address of Correspondence: Dr. Mohammad Emdadul Hoque Miah, 250 bedded general hospital , Gopalgonj, Bangladesh. Email-dremdad99@gmail.com 
die within one year than patients with no ST depression and risk increased to ten folds where e"2mm ST segment depression extends more than one regions. ST segment depression and its association with angiographic severity of coronary artery diseases was assessed in few studies. ${ }^{14-15}$

Patients of NSTE ACS are a large number of admissions to coronary care units where 12-lead electrocardiogram (ECG) provides the simple available and earliest objective information for risk stratification. The qualitative importance of ST segment depression on the baseline ECG in patients of non-ST segment elevation acute coronary syndrome is recognized but quantification of this phenomenon and its correlation with angiographic severity of coronary artery disease is rarely used in the modern era of aggressive pharmacological and interventional therapy, which might be a better independent risk predictor of coronary artery diseases in this group of patents.

\section{Methods:}

This was a cross sectional study carried out in the department of cardiology, National Institute of Cardiovascular Diseases (NICVD), Dhaka, in the period of January 2011 to May 2011. Sampling population was Patients of non-ST segment elevation acute coronary syndrome who admitted into and underwent coronary angiography in hospital. Total Sample size was 105. Patients admitted into hospital with at least one of the following three criteria: i)Angina occurring at rest (or minimal exertion) and usually lasting $>20$ minutes (if not interrupted by nitroglycerin administration), ii) Being severe and described as frank pain, and of new onset (i.e., within 2 month), iii) Occurring with a crescendo pattern (i.e., more severe, prolonged, or frequent than previously).patients with i) ST segment elevation in admission ECG or appearance of new ST segment elevation over the course of hospital stay, ii) Ventricular hypertrophy, iii) Bundle branch block, iv) Paced rhythm, v) Wolf-Parkinson-White syndrome, vi) Previous PTCA or CABG cases, vii) Serious co morbid condition like chronic kidney disease or cerebrovascular disease were excluded from the study.

\section{Study procedure:}

Patients with NSTE ACS admitted into the Department of Cardiology NICVD had been evaluated. Considering inclusion and exclusion criteria patient was selected for the study.12 lead ECG as recorded in the emergency department was analyzed and divided into three groups: Group I: No $(<1 \mathrm{~mm})$ ST segment depression, Group II:1$2 \mathrm{~mm}(\geq 1$ to $<2 \mathrm{~mm}$ ) ST segment depression in two or more contiguous leads Group III: e" 2 mm ST segment depression in two or more contiguous leads. Cumulative sum of ST segment depression and number of leads in ST segment depression was also measured. ST segment shift was measured in all leads at $80 \mathrm{~ms}$ after the $\mathrm{J}$ point for ST segment depression. ST segment depression was measured at 1-mm intervals, with every fraction rounding to the nearest whole number. The distribution of ST segment depression was examined in three regions anterior (leads V1 to V4), inferior (leads II, III and aVF) and lateral (leads I, aVL, V5 and V6). A particular region was deemed to have ST segment depression if any two contiguous leads comprising the region had ST segment depression.

Angiographic severity of coronary artery disease was assessed by 2 scoring system Vessel score and Friesinger index. ${ }^{16}$ According to Friesinger index severity of coronary artery disease was assessed and categorized into two groups:

1) Insignificant $\mathrm{CAD}$ (Friesinger index $<5)$.

2) Significant CAD (Friesinger index $\geq 5$ ).

Magnitude of ST segment depression was compared with angiographic severity.

\section{Data analysis:}

Data was presented as frequency and percents for categorical variables and as mean with standard deviation for quantitative variables. Categorical variables were analyzed by chi-square test. Quantitative variables were analyzed by t-test or ANOVA. Correlations between magnitude of ST segment depression and angiographic severity was measured by Pearson's correlation test. $p$ value $<0.05$ was considered as significant. Statistical analysis was performed with SPSS, version 16.0 (SPSS Inc).

\section{Results:}

In this study total 105 patients were study population. Out of all cases 60(57.1\%) was in group I, 20(19.0\%) was in group II and rest 25(23.8\%) was in group III. Total number of male patient 
was $81(77.1 \%)$ and female patient was $24(22.9 \%)$. Male female ratio was 3.37:1 in the whole study population. There was no significant impact of sex distribution among the three ST segment groups. The mean age was $50.72 \pm$ years $7.32 \pm 7.89$ years and $53.90 \pm 8.31$ years in group I,II and III respectively. Maximum frequency was found in the age group of 51-60 years. There was statistically significant $(p<0.001)$ difference in mean age among the three ST segment groups in ANOVA test.

The mean BMI of whole study population was $24.55 \pm 3.17 \mathrm{~kg} / \mathrm{m}^{2}$. There was no statistically significant difference in mean BMI among the groups. Hypertension was the most common risk factor present in 58(55.2\%) patients followed by Smoking in 48(45.7\%) and Diabetes mellitus in $36(34.6 \%)$. There was no significant difference in traditional risk factors among the three groups.

Distribution of study population according to ST segment depression found that higher the magnitude of ST segment depression higher the Friesinger index and vessel score, which is shown in Table II and III. Friesinger index difference was statistically significant $(\mathrm{p}<0.001)$ among three groups in chi-square test (Table III).

\section{Table-I}

Baseline clinical variables in the study population $(n=105)$.

\begin{tabular}{lcccc}
\hline Variables & Group I & Group II & Group III & p value \\
\hline Distribution of population & $60(57.1 \%)$ & $20(19.0 \%)$ & $25(23.8 \%)$ & \\
Age & $50.72 \pm 7.0$ & $53.90 \pm 8.31$ & $52.90 \pm 89$ & $\mathrm{NS}$ \\
$\quad$ Sex (Male) & $44(73.3 \%)$ & $17(85 \%)$ & $20(80 \%)$ & $\mathrm{NS}$ \\
Risk factors: & & & \\
$\quad$ Smoking & $27(45 \%)$ & $9(45 \%)$ & $12(45.7 \%)$ & $\mathrm{NS}$ \\
Hypertension & $32(53.3 \%)$ & $11(55 \%)$ & $15(60 \%)$ & $\mathrm{NS}$ \\
Diabetes Mellitus & $22(37.3 \%)$ & $5(25 \%)$ & $9(36 \%)$ & $\mathrm{NS}$ \\
Positive F/H of CAD & $12(23.0 \%)$ & $2(11.1 \%)$ & $6(27.3 \%)$ & $\mathrm{NS}$ \\
Dyslipidemia & $18(62.0 \%)$ & $5(83.3 \%)$ & $2(18.1 \%)$ & $\mathrm{NS}$ \\
BMI & $24.96 \pm 3.45$ & $23.85 \pm 2.38$ & $24.55 \pm 3.17$ & $\mathrm{NS}$ \\
Pulse & $81.52 \pm 12.09$ & $82.95 \pm 10.03$ & $82.87 \pm 13.14$ & $\mathrm{NS}$ \\
SBP & $121.81 \pm 16.05$ & $127.37 \pm 21.62$ & $128.4 \pm 25.11$ & $\mathrm{NS}$ \\
DBP & $81.12 \pm 9.95$ & $79.74 \pm 9.04$ & $81.57 \pm 10.80$ & $\mathrm{NS}$ \\
LVEF & $60.38 \pm 10.75$ & $60.19 \pm 7.78$ & $59.51 \pm 9.95$ & $\mathrm{NS}$ \\
Sum of ST segment depression & 0 & $3.95 \pm 1.98$ & $9.28 \pm 3.69$ & $<0.001^{\mathrm{S}}$ \\
Num. of leads in ST depression & 0 & $3.55 \pm 1.46$ & $4.92 \pm 1.77$ & $<0.001^{\mathrm{S}}$ \\
Vessel score & $0.88 \pm 0.99$ & $1.40 \pm 1.18$ & $2.04 \pm 1.06$ & $<0.001^{\mathrm{S}}$ \\
Friesinger index & $3.98 \pm 4.38$ & $6.25 \pm 4.55$ & $8.92 \pm 3.85$ & $<0.001^{\mathrm{S}}$ \\
\hline
\end{tabular}

$\mathrm{S}=$ Significant, NS= Not significant, $\mathrm{p}$ value derived from appropriate statistical analysis

Table-II

Distribution of patients according to Friesinger index $(n=105)$.

\begin{tabular}{lccccc}
\hline Friesinger index & Group I (n=60) & Group II (n=20) & Group III (n=25) & Total & p value \\
\hline $0-4$ & $37(61.7 \%)$ & $8(40.0 \%)$ & $4(16 \%)$ & $49(46.7 \%)$ & $(\mathrm{p}<0.001)$ \\
$5-10$ & $18(30.0 \%)$ & $7(35.0 \%)$ & $11(44 \%)$ & $36(34.3 \%)$ & \\
$11-15$ & $5(8.3 \%)$ & $5(25.0 \%)$ & $10(40 \%)$ & $20(19.0 \%)$ & \\
\hline
\end{tabular}

${ }^{\#} \mathrm{p}$ value derived from chi square test 


\section{Table-III}

Distribution of patients according to vessel score $(n=105)$.

\begin{tabular}{lcccc}
\hline Vessel score & Group $(\mathrm{n}=60)$ & Group II(n=20) & Group III (n=25) & Total \\
\hline 0 & $29(48.3 \%)$ & $6(30.0 \%)$ & $4(16.0 \%)$ & $39(37.1 \%)$ \\
1 & $13(21.6 \%)$ & $5(25.0 \%)$ & $1(4.0 \%)$ & $19(18.1 \%)$ \\
2 & $14(23.3 \%)$ & $4(20.0 \%)$ & $10(40.0 \%)$ & $28(26.6 \%)$ \\
3 & $4(6.6 \%)$ & $5(25.0 \%)$ & $10(40.0 \%)$ & $19(18.1 \%)$ \\
\hline
\end{tabular}

Table-IV

ST segment depression and severity of CAD according to Friesinger index $(n=105)$.

\begin{tabular}{lccccc}
\hline Significant CAD & GroupI(n=60) & Group II(n=20) & Group III $(\mathrm{n}=25)$ & Total & p value \\
\hline Present(FIe"5) & $23(38.3 \%)$ & $12(60.0 \%)$ & $21(84.0 \%)$ & $56(53.3 \%)$ & $(\mathrm{p}<0.001)$ \\
Absent $(\mathrm{FI}<5)$ & $37(61.7 \%)$ & $8(40.0 \%)$ & $4(16.0 \%)$ & $49(46.6 \%)$ & \\
\hline
\end{tabular}

$\mathrm{m}$ p value derived from chi square test.

Friesinger index (FI) e"5= Significant CAD Friesinger index $(\mathrm{FI})<5=$ Insignificant CAD

Significant CAD was found in $38.3 \%$ cases in Group I, $60 \%$ in Group II and $84 \%$ in Group III which found incremental rate of significant CAD proportional to magnitude of ST segment depression. Cumulative sum of the ST segment depression $(r=0.435 ; p<0.001)$ and number of leads in ST segment depression $(r=0.446 ; p<0.001)$ both found positive correlation with Vessel score which means that higher the total burden of ST segment depression higher the severity of coronary disease.

Similarly cumulative sum of the ST segment depression $(r=0.446 ; p<0.001)$ and number of leads in ST segment depression $(r=0.453 ; p<0.001)$ also revealed positive correlation with Friesinger index which means that higher the total burden of ST segment depression higher the severity of coronary disease.

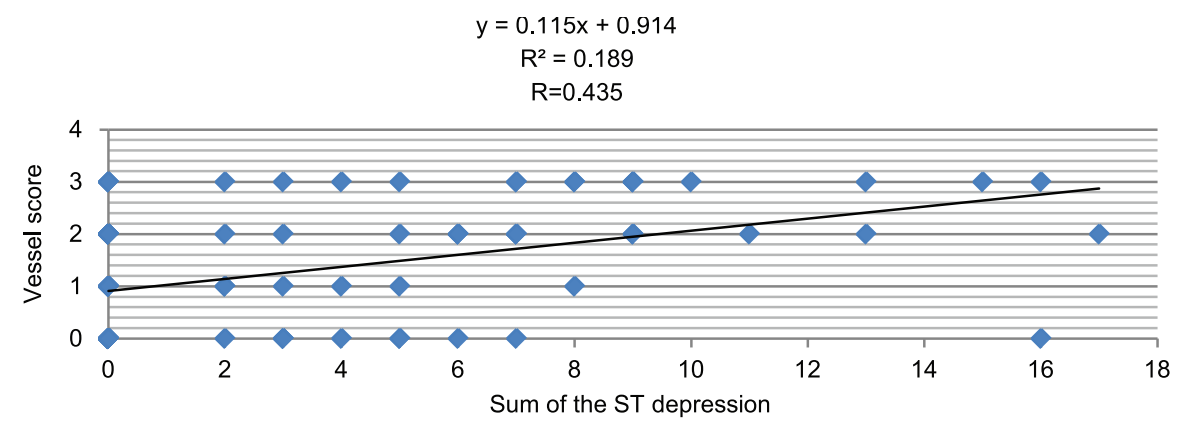

Fig.-1: The scatter diagram shows significant positive correlation $(r=0.435)$ between Vessel score and sum of ST segment depression in the study patients. $(n=105)$

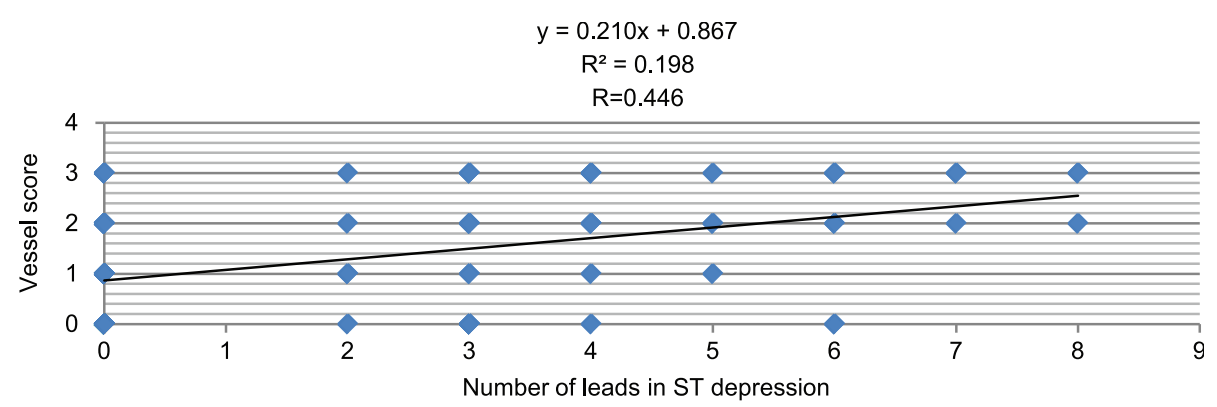

Fig.-2: The scatter diagram shows significant positive correlation $(r=0.446)$ between Vessel score and number of leads in ST segment depression in the study patients. ( $n=105$ 


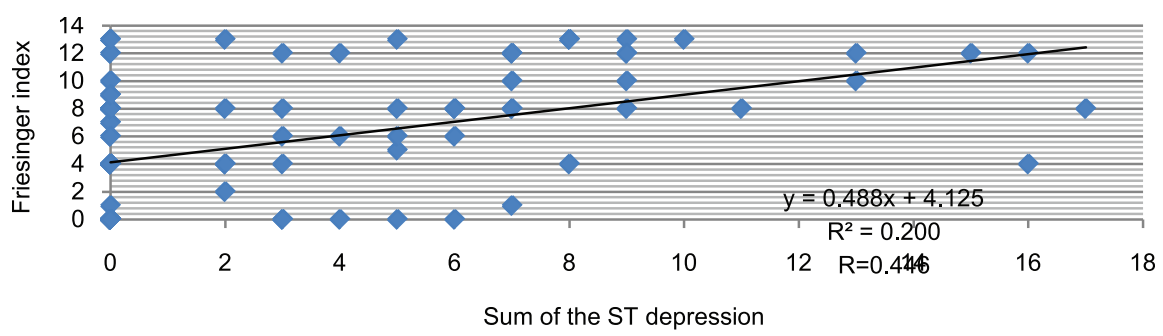

Fig.-3: The scatter diagram shows significant $(r=0.446)$ between Friesinger index and sum of ST segment depression in the study patients. $(n=105)$

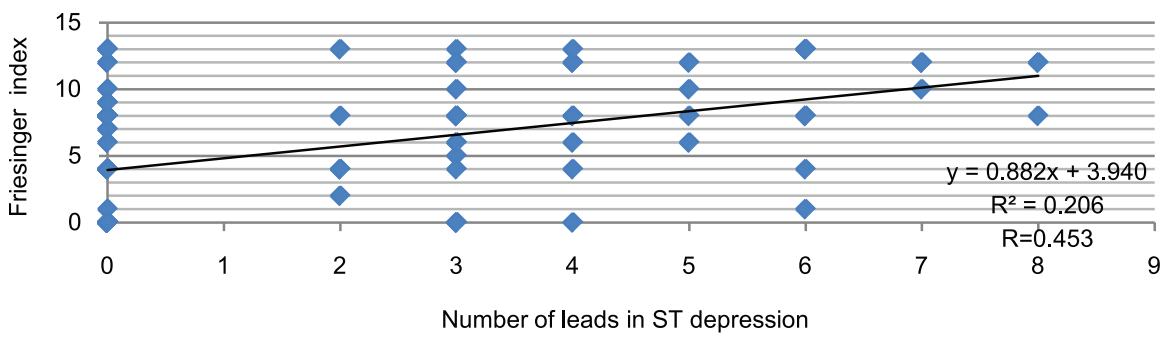

Fig.-4: The scatter diagram shows significant positive correlation $(r=0.453)$ between Friesinger index and number of leads in ST segment depression in the study patients. $(n=105)$

\section{Discussion:}

The most important finding of this study is that higher the magnitude of ST segment depression higher the severity of coronary artery disease. It is remarkable that the magnitude of ST segment depression in NSTE ACS is assessed hear in three different way such as qualitative ST segment depression (No ST depression, 1-2 $\mathrm{mm}$ ST depression and $\geq 2 \mathrm{~mm}$ ST segment depression ), cumulative sum of ST segment depression and number of leads in ST segment depression.

Correlation study found that cumulative sum of ST segment depression and number of leads in ST segment depression both are positively correlated with angiographic severity of coronary artery disease according to Friesinger index and vessel score.

José A et al. found that that the presence, magnitude and extent of ST segment depression were associated with an increased mortality. ${ }^{8} \mathrm{ST}$ segment depression in two or more lateral leads was associated with (odds ratio 3.5, $95 \%$ CI: 1.2 to 10.6) significantly increased mortality. Qualitative analysis of ST segment depression and its impact on the outcome of coronary artery disease found that $\geq 2 \mathrm{~mm}$ ST segment depression was 6 times more likely to die within one year than patients with no ST segment depression. ${ }^{10}$. Kaul et al. found that quantitative ST segment depression and cardiac troponin $\mathrm{T}$ are complimentary in assessing risk among ACS patients and both should be employed to determine prognosis and assist in medical decision making. ${ }^{10}$ Khan found that in hospital complications, in terms of mortality, acute LVF, significant arrhythmias, cardiogenic shock and STEMI was more in $\geq 2 \mathrm{~mm}$ ST segment depression group in comparison to less severe ST segment depression groups. ${ }^{12}$

Ullah et al. ${ }^{15}$ found angiographic correlation with lateral (I,avL, $\mathrm{V}_{5}, \mathrm{~V}_{6}$ ) ST segment depression, Yuri $\mathrm{B}$ et al. ${ }^{17}$ found angiographic correlation with isolated anterior ST segment depression, but present study found angiographic correlation with ST segment depression of any region in 12 lead admission ECG.

Savonitto et al. ${ }^{18}$ found that in patients of NSTE ACS the cumulative sum of ST segment depression in all ECG leads was a powerful predictor of all cases mortality at 30 days, independent of clinical variables and correlated with the extent and severity of coronary artery diseases.

This present study which was intended to find out the association between magnitude of ST segment depression and severity of coronary artery diseases 
revealed that magnitude of ST segment depression positively correlates with the angiographic severity of coronary artery diseases in non- ST segment elevation acute coronary syndrome patients.

\section{Conclusion:}

Magnitude of ST segment depression found significantly correlated with severity of coronary artery disease. Cumulative sum of ST segment depression and number of leads in ST segment depression also found significantly correlated with severity of coronary artery disease. This may provide a very simple and effective base line predictor of severity of coronary artery disease in the patients of non ST segment elevation acute coronary artery syndrome.

\section{Conflict of Interest - None.}

\section{References:}

1. Chaturvedi V \& Bhargava B. Health care delivery for coronary heart disease in India- where are we headed? Am Heart Hosp J 2007; 5: 32-37.

2. Murray CJL \& Lopez AD. Global health statistics, Global burden of disease and injury series. Harvard school of public health: Boston, 1996.

3. Cannon CP. Optimizing the treatment of unstable angina. J Thromb Thrombolys 1995; 2: 205-218.

4. Siddique MA, Banik D, Sultan MA, Rahman MA, Pervin T, Mahmood M, Haque KMHSS, Jamil AA. Cardiovascular risk factor profile of unstable angina patients in Bangladesh. University Heart Journal 2005; $1: 1$.

5. Cannon CP, McCabe CH, Stone PH, Rogers WJ, Schactman M, Thompson BW, et al. The TIMI III Registry ECG Ancillary Study Investigators. The electrocardiogram predicts one-year outcome of patients with unstable angina and non-Q-wave myocardial infarction: results of the TIMI III Registry ECG Ancillary Study. J Am Coll Cardiol 1997; 30:133-140.

6. Diderholm E, Andren B, Frostfeldt G, Genberg $M$, Jernberg T, Lagerquist B, et al. the FRISC Investigators. $S T$ depression in ECG at entry indicates severe coronary lesions and large benefits of an early invasive treatment strategy in unstable coronary artery disease. The FRISC II ECG sub study. Eur Heart J 2002; 23:41-49.

7. Hyde TA, French JK, Wong CK, Straznicky IT, Whitlock RM, White HD. Four-year survival of patients with acute coronary syndromes without ST-segment elevation and prognostic significance of $0.5 \mathrm{~mm} \mathrm{ST}$ segment depression. Am J Cardiol1999; 84:379-385.
8. Barrabés JA, Figueras J, Moure C, Cortadellas J, SolerSoler J. Prognostic significance of ST segment depression in lateral leads $\mathrm{I}, \mathrm{aVL}, \mathrm{V}_{5}$ and $\mathrm{V}_{6}$ on the admission electrocardiogram in patients with a first acute myocardial infarction without ST segment elevation. J Am Coll Cardiol 2000; 35:1813-1819.

9. Krone RJ, Greenberg H, Dwyer EM, Klieger RE, Boden WE and the Multicenter Diltiazem Post infarction Trial Research Group. Long-term prognostic significance of $S T$-segment depression during acute myocardial infarction. J Am Coll Cardiol 1993; 22: 361-367.

10. Kaul P, Fu Y, Chang Wc, Harrington RA, Wagner GS, Goodman SG, et al. GUSTO-IIB and PARAGON-A Investigators. Prognostic value of $S T$ segment depression in acute coronary syndromes: insights from PARAGON-A applied to GUSTO-IIB. J Am Coll Cardiol 2001;.38:64-71.

11. Kaul P, Newby LK, Fu Y, Hasselblad V, Mahaffey KW, Christenson RH, et al. Troponin T and quantitative STsegment depression offer complementary prognostic information in the risk stratification of acute coronary syndrome patients. J Am Coll Cardiol 2003; 41; 371380.

12. Rahman KMM. Extent of ST segment depression predicts in-hospital outcome in non-ST segment elevation acute coronary syndrome. Dhaka, Bangladesh: University of Dhaka. 2008.

13. Langer A, Freeman MR, Armstrong PW. ST segment shift in unstable angina: pathophysiology and association with coronary anatomy and hospital outcome. J Am Coll Cardiol 1989; 13:1495-1502.

14. Sclarovsky S, Rechavia E, Strasberg B, Sagie A, Bassevich R, Kusniec J, et al. Unstable angina: $S T$ segment depression with positive versus negative $T$ wave deflections-clinical course, ECG evolution, and angiographic correlation. Am Heart J 1988;116: 933-941.

15. Ullah M, Khalequzzaman M, Habib SMA, Kar N, Islam MN. Angiographic correlation of ST segment depression on admission ECG in patient worth NSTEMI. Bangladesh Heart Journal 2006; 21(2): 72-77.

16. Ringqvist I, Fisher LD, Mock M, Devis KB, Wedel H, Chaitman BR, et al. Prognostic value of Angiographic Indices of coronary artery disease from the Coronary Artery Surgery Study (CASS). J Clin Invest 1983; 71:1854-1866.

17. Yuri B, Tung PP, Nohanavelu S, Zorkun C, Stephen D, Elliott MW, et al. TINI study Group. Angiographic and clinical outcomes among patients with acute coronary syndromes presenting with isolated anterior STsegment depression. J Am Coll Cardiol Intv 2010; 3: 806-811.

18. Savonitto S, Cohen MG, Politi A, Hudson MP, Kong DF, Huang Y, et al. Extent of ST-segment depression and cardiac events in non-ST-segment elevation acute coronary syndromes. Eur Heart J 2005; 26: 2106-2113. 